\title{
Relationship between Family Function with Stress, Anxiety and Depression of Air Force Pilots in Isfahan-2019-2020
}

Zand bina. N1
${ }^{*}$ Keshvari. $\mathrm{M}^{2}$
Kheirabadi. Gh ${ }^{3}$
1- MSc Student Nursing, Nursing
Department, Isfahan University
of Medica Sceinces, Isfahan,
Iran.
2- ${ }^{*}$ Corresponding Author)
Ph.D. in Nursing, Associate
Professor, Community Health
Nursing Department, Faculty of
Nursing and Midwifery, Isfahan
University of Medical Sciences,
Isfahan, Iran.
Email: zand_7611@yahoo.com
3- MD, in Psychiatrist, Associate
Professor, Behavioral Research
Center, Psychiatry Department,
Isfahan University of Medical
Sciences, Isfahan, Iran.

Zand bina. $\mathrm{N}^{1}$

MSc Student Nursing, Nursing Department, Isfahan University of Medica Sceinces, Isfahan,

$\left({ }^{*}\right.$ Corresponding Author) Ph.D. in Nursing, Associate Professor, Community Health Nursing and Midwifery, Isfahan University of Medical Sciences, tahan, Iran. Sciences, Isfahan, Iran.

\begin{abstract}
Introduction: The importance of the Air Force's ability to protect and defend any country is obvious. The well-performed air force depends on the capabilities, mental and physical health of staff. Family as an environmental factor plays a significant role in the development and maintenance of mental health disorders.
\end{abstract}

Objective: This study aimed to investigate the relationship between family function and stress, anxiety and depression in Isfahan Air Force pilots during 2019-2020.

Materials and Methods: In this descriptive study, 120 military air force pilots completed the standard family functioning (FAD), anxiety, stress and depression (DASS) questionnaires. After excluding invalid questionnaires, data were collected from 103 individuals and analyzed in SPSS20. The significant level is considered 0.05 .

Results: Linear regression analysis showed that the family function was scored 0.16 , 0.05 and 0.05 in in depression, anxiety and stress, respectively. The family function was a significant predictor of depression, anxiety and stress in participants. The results showed that based on beta coefficients, each $0.25,0.24$ and 0.24 change in family performance score resulted in a significant change in participants' depression, anxiety and stress scores, respectively $(\mathrm{P}<0.05)$.

Discussion and Conclusion: Based on results of this study, it can be concluded that decreasing family function increases anxiety, depression and stress in pilots. Therefore military families should be considred.

Keywords: Anxiety, Depression, Family Function, Military, Pilot, Stress. 


\title{
بررسى ارتباط عملكرد خانواده با استرس، اضطراب و افسر دَى خلبانان نيروى هوايى اصفهان در سال 91-91
}

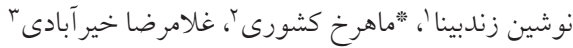

جكيده

مقدمه: اهميت توان نيروى هوايى در حفاظت و دفاع از هر كشورى آشكار است. عملكرد نيروهاى انسانى در هر سازمانى به توانايىها و سلامت روانى و جسمانى كار كنان آن بستگى دارد. خانواده به عنوان يك عامل محيطى در كاركرد سلامت

$$
\text { روان افراد نقش دارد. }
$$

هدف: اين مطالعه با هدف بررسى ارتباط عملكرد خانواده با استرس، اضطراب و افسردىى خلبانان نيروى هوايى اصفهان

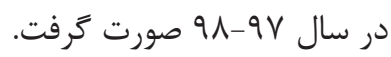
مواد و روشها: در اين مطالعه توصيفى تعداد • بl نفر از خلبانان نيروى هوايى شهر اصفهان مورد بررسى قرار كرفتند. شركت كنند كان يرسشنامههاى استاندارد عملكرد خانواده (FAD)، اضطراب، استرس و افسردىى (DASS) را تكميل كردند. بعد از حذف يرسشنامههاى نامعتبر دادهاى ؟ • ا نفر مورد ارزيابى قرار كَرفت. دادههاى جمعآورى شده در نرمافزار

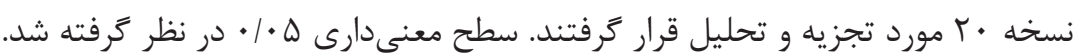

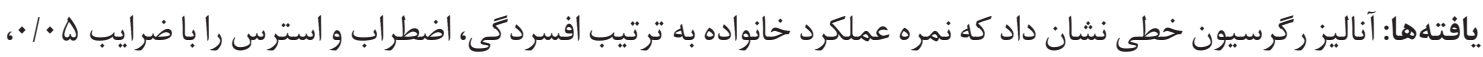

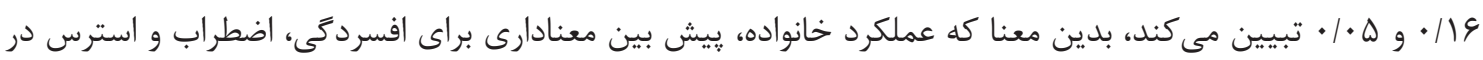

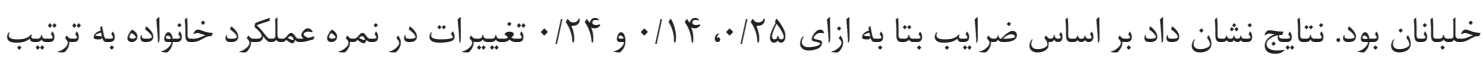

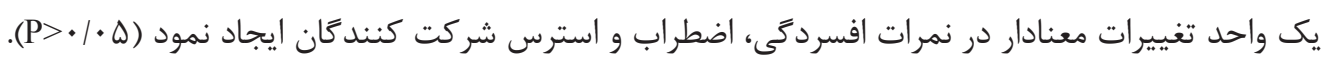
بحث و نتيجه كيرى: بر اساس يافتههاى تحقيق حاضر مىتوان نتيجه كرفت كاهش در عملكرد خانواده موجب افزايش

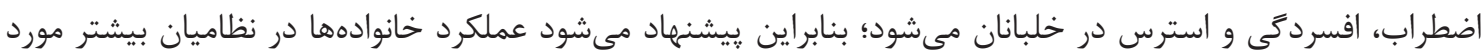
توجه قرار كيرد.

كلمات كليدى: استرس، اضطراب، افسردىى، خلبان، عملكرد خانواده، نظامى.

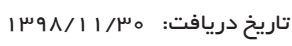

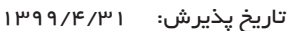

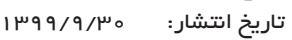

(1). نيروى نظامى سازمانى است مسلح در تابعيت فرماندهى كل

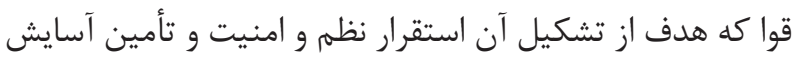

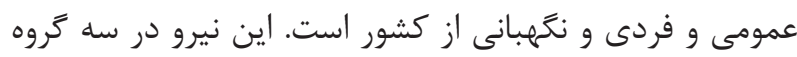

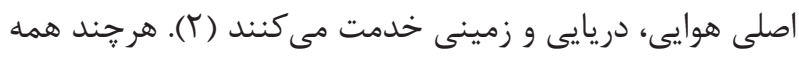
نيروهاى نظامى در جايخاه خود در حفظ امنيت و نظم نقش مهمى
قدرت ملى هر كشورى متأثر از قدرت اقتصادى، سياسى، اجتماعى،

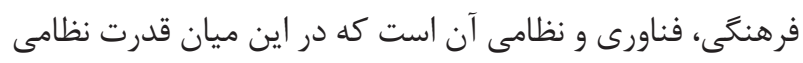

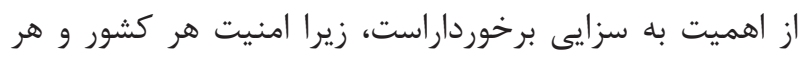

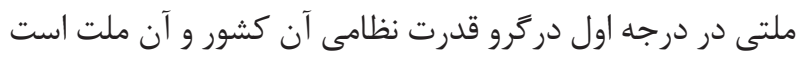


از شركت كنند

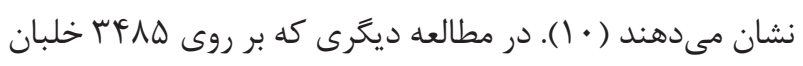

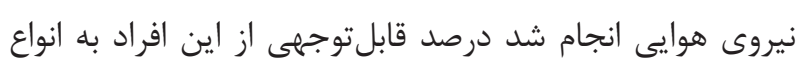

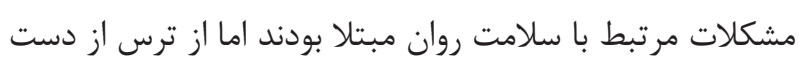

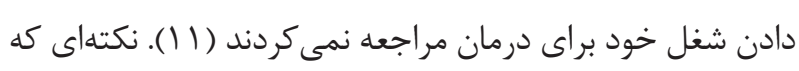

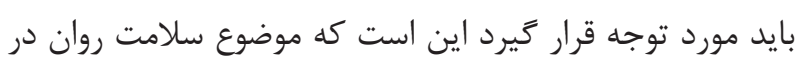
خصوص خلبانها تنها يك مسئله شخصى نيست. بلكه ممكن

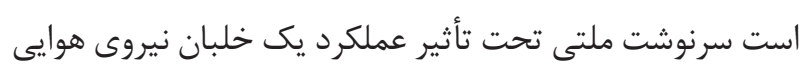

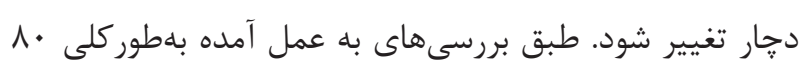

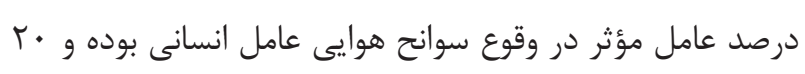

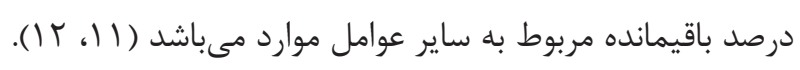

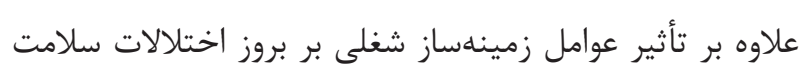

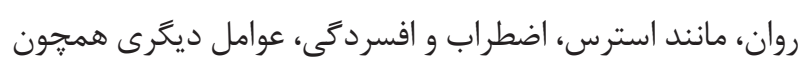
زرنتيك، محيط كارى، وضعيت اقتصادى، اجتماعى و خانوادىى إنى

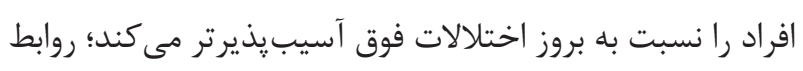

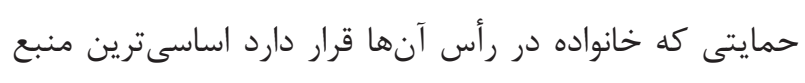

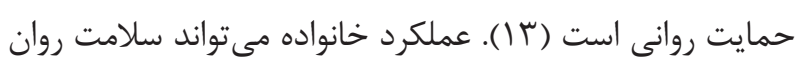
را در كروههاى سنى و اجتماعى مختلف تحت تأثير قرار دهد

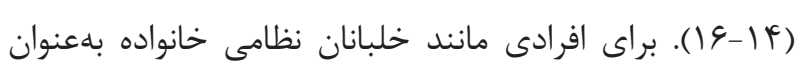
محيطى امن و حمايت

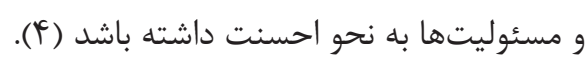
مطالعات متعددى نقش اساسى خانواده را در سلامت خانواده

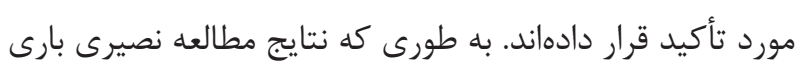

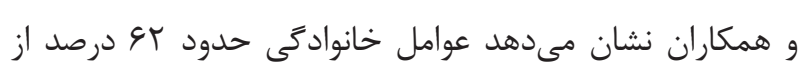
واريانس استرس و اضطراب كار كنان نظامى را يِيشبينى مى كنداند

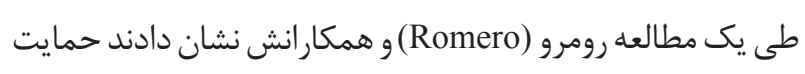

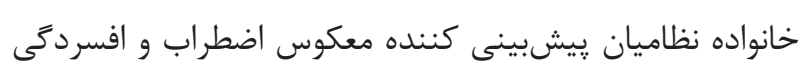

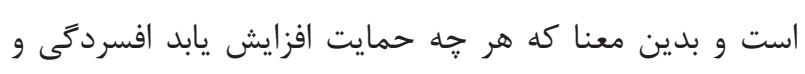

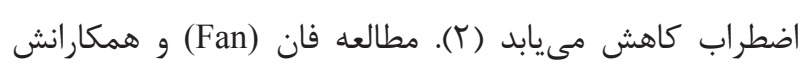
نشان مى دهد فشار همزمان محيط كار و حمايتكر نبودن خانواده

موجب افسردگى در كاركنان نظامى مى شود (IV) با در نظر كرفتن اينكه نتايج مطالعات مرور شده در در بالا نشان مدان مى دهد استرس و اضطراب خلبانان مىتواند موجبات خطرات

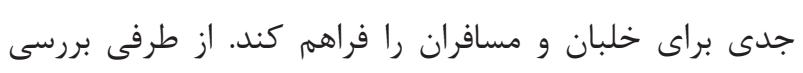

ايفا مى كنند؛ اما يكى از اساسىترين معيارهاى سنجش برترى نظامى در هر كشورى به قدرت نيروى هوايى آن كشور وابسته

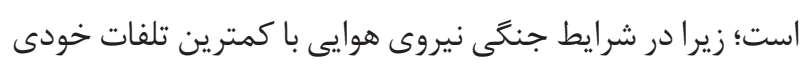

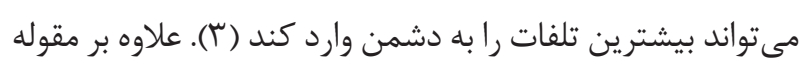

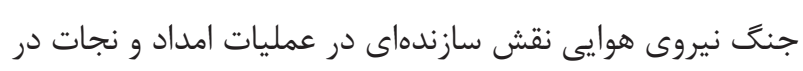
سراسر جهان ايفا مى كند (r). يك خلبان در شرايط و بحرانهاى مختلف جوى، نظامى و فنى آنى

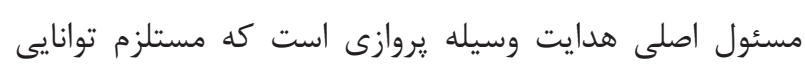

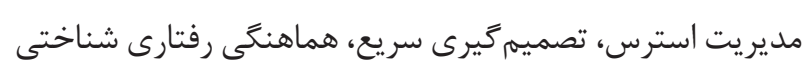

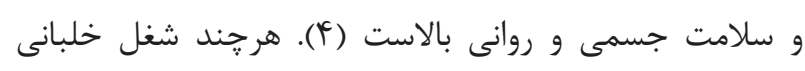

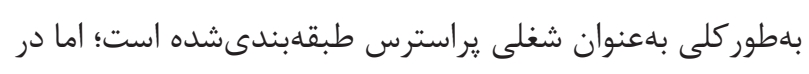

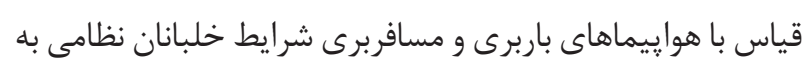

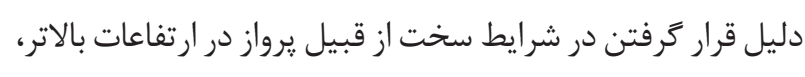

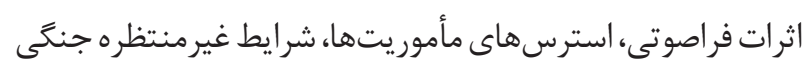
و نجات به مراتب يِيجيدهتر است (ه). به طورى كه نتايج مطالعات نيز مؤيد استرس بالاتر خلبانان نظامى نسبت به خلبانان مسافربرى است (9). فشار كارى بالا، محدوديت زمانى، عدم اطمينان و وضعيتهاى غيرمنتظره بهعنوان بخش جدايىنايذير كار خلبانان نظامى با افزايش مداوم هورمون هاى استرس، حافظه كارى، توجه

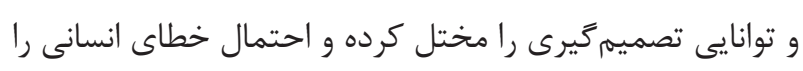

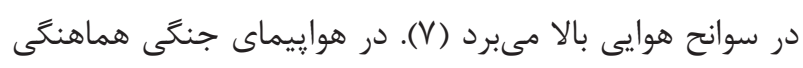

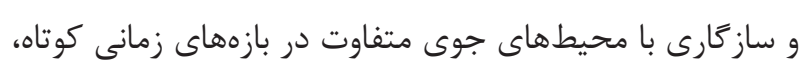

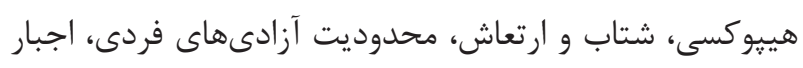

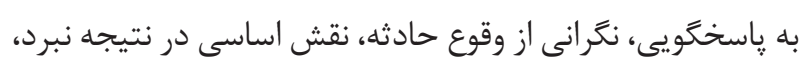

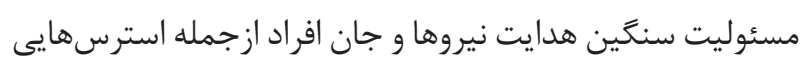

است كه يك خلبان نظامى تجربه مى كند (؟).

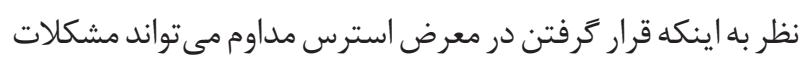

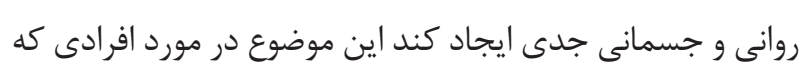
حافظ جان و امنيت مردم يك كشور هستند، اهميت بيشترى ييدا

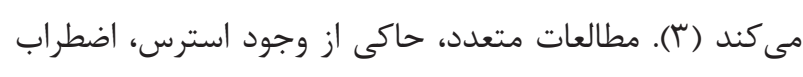

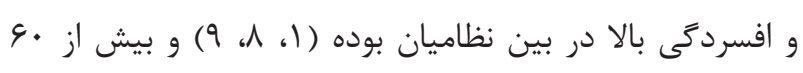

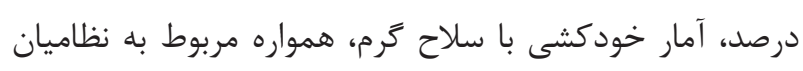

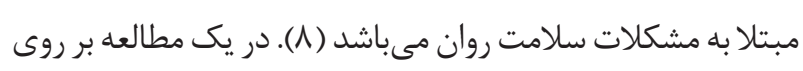

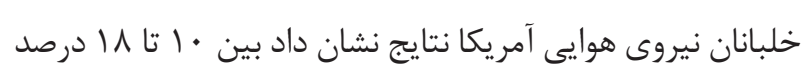


كمتر نشانه عملكرد سالمتر است. در يزوهش يوسفى از طريق

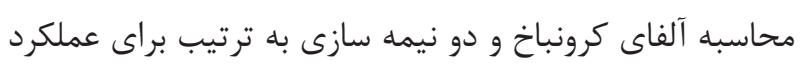

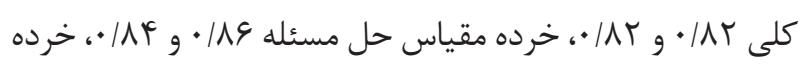

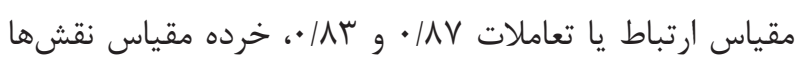

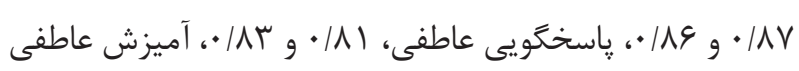

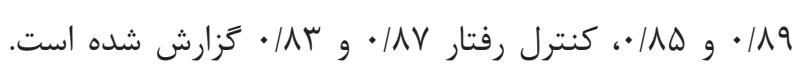
اعتبار سازه يرسشنامه با تحليل عاملى تائيدى نيز به صورت • عاملى تائيد شده است (1) (1).

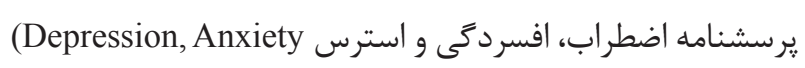
1990 and Stress Scale) طراحى و ساخته شد. اين برسشنامه سه وضعيت روانى اضطراب،

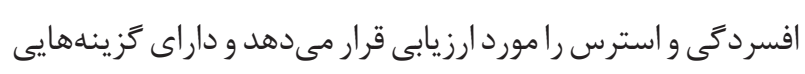

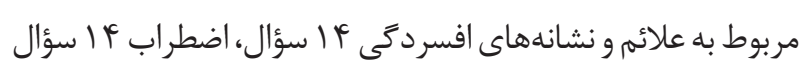

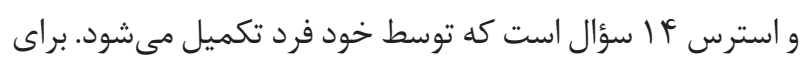

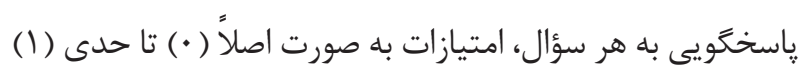

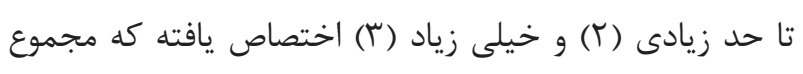

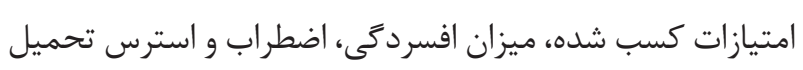

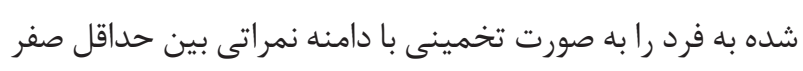

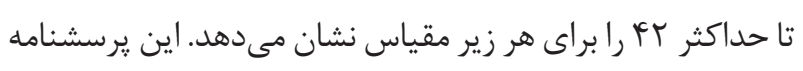
در ايران توسط افضلى و همكاران مورد بررسى و تأييد قرار كرفته

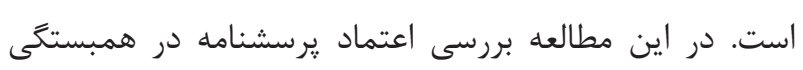

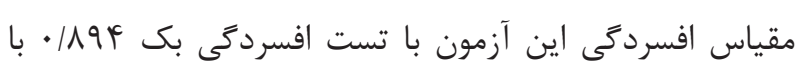

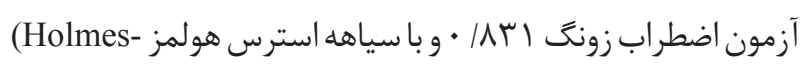

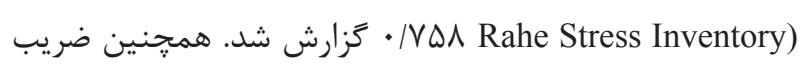

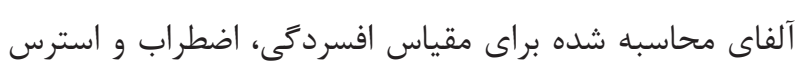

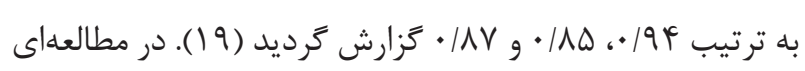

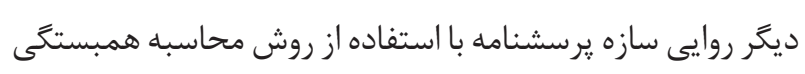
بين نمرههاى دو مقياس اضطراب و افسردىى با نمرههاى مقياس

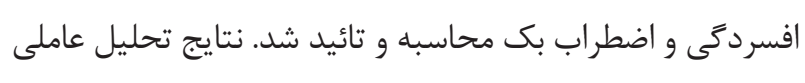

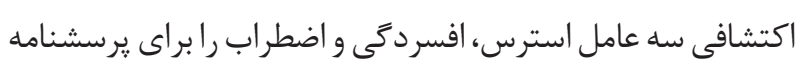
تائيد كرد (· (r). تجزيه و تحليل دادهها با استفاده از SPSS نسخه • ب انجام شد.

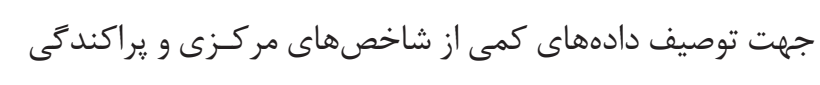

مشكلات سلامت روان خلبانان در ارتباط با خانواده كمتر مورد

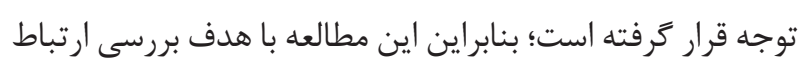

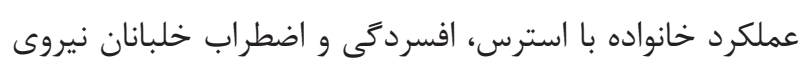

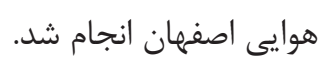

\section{مواد و روشها}

اين يزوهش توصيفى از نوع همبستخى مقطعى مى مواشد. جامعه رونا

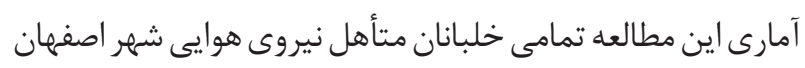
در سال 19 إ بود. حجم نمونه با استفاده از فرمول حجم نمونه كوكران براى مطالعات همبستخى به صورت زير محاسبه شد: $N=\left(Z_{1}+Z_{r}\right)^{r} \times(1-r)^{r} / r^{r}$

تعداد نمونه با توجه به اين رابطه حداقل . •ا نفر به دست آمد

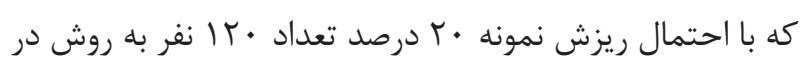

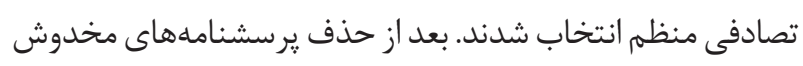

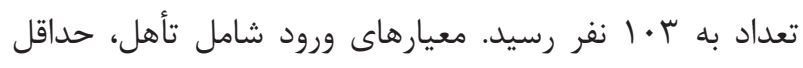

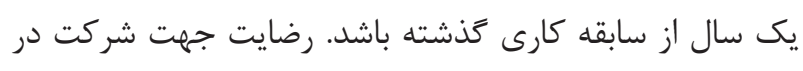

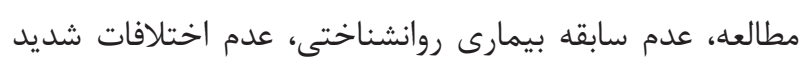
زناشويى اخير، عدم تجربه حادثه استرس زاى در شش ماهه اخير

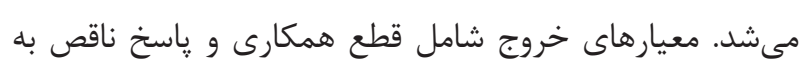

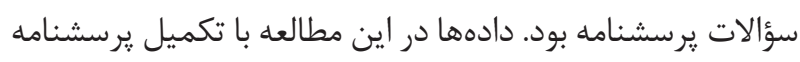
جمعيت شناختى (سن، تحصيلات، وضعيت تأهل، تحصيلات

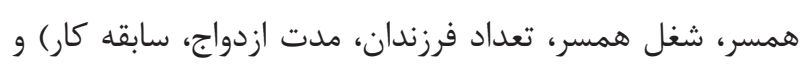

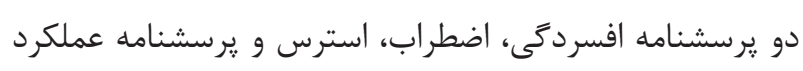

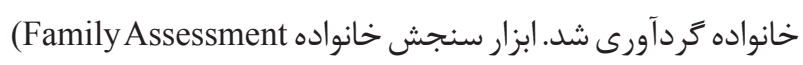
(Epstein) يك ابزار • • سؤالى است توسط إيستاين Device)

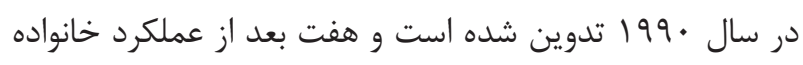
را مىسنجد كه شامل: حل مسئله (Problem Solving)، ارتباط

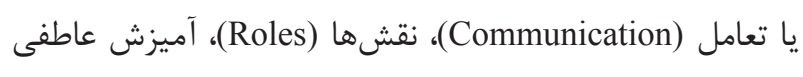

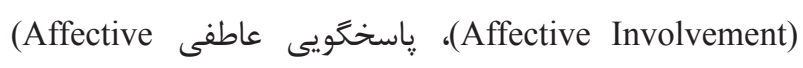
(Responsiveness)

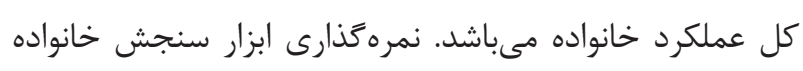

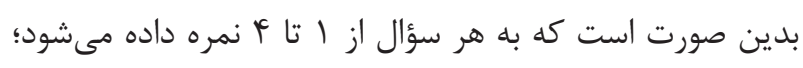

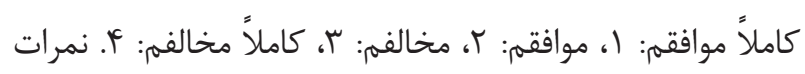


(درصد) استفاده شد. جهت تجزيه و تحليل دادههاى كيفىهاى يافتهها

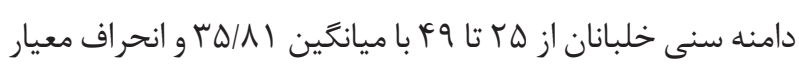
ه/Dq سال بود. ضمناً ميانگين سابقه كار آنها

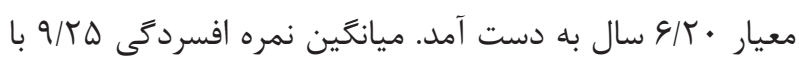

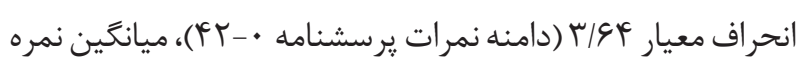

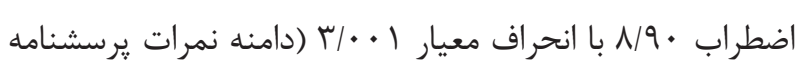
و و ميانخين نمره استرس خلبانان و/9F-•

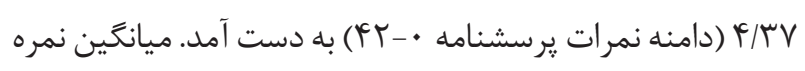

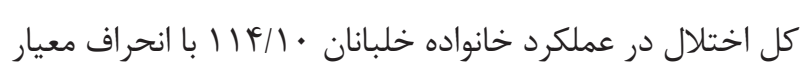

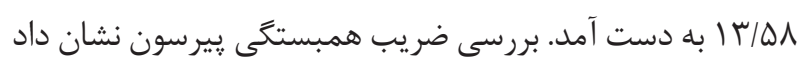

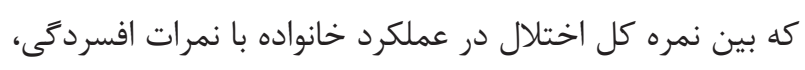
اضطراب و استرس رابطه مستقيم وجود دارد (ه •|•P). ضريب همبستخى يیيرسون نشان داد سن، سن همسر، سابقه كار و مدت زمان ازدواج با افسردكى در خلبانان همبستخى مثبت داشت (P>•/ • (P>). با افزايش سابقه كار ميزان اضطراب نيز افزايش يافت

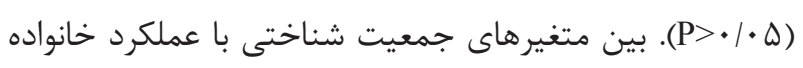
و استرس ارتباط معنادار مشاهده نشد (جدول (). بنابراين جهت تحليل رگرسيون اقدام شد.
رتبهاى از روش همبستخى اسيّرمن، جهت بررسى ارتباط دادههاى كيفى اسمى از روش لوجستيك و براى بررسى ارتباط دادههاى

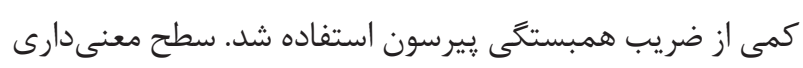
معادل ه • • • در نظر گرفته شد. اين طرح بعد از طى مراحل تصويب در دانشعاه علوم يزشكى اصفهان و اخذ موافقت نامه كميته اخلاق دانشعاه با كد

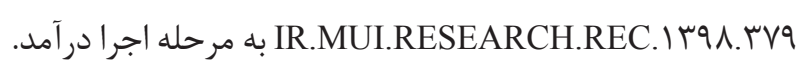
ضمن اينكه به آنها اعلام شد كه در هر مرحله از يزوهش، مى توانند از شركت در تحقيق انصراف دهند. در طى اجرا و انتشار نتايج، كليه حقوق دانشگاه و نمونهها بر اساس (COPE) و اصول كميته اخلاق نشر بيانيه هلسينكى (Helsinki) رعايت شد، همجنين در راستاى رعايت نكات اخلاقى و محرمانه بودن دادهها به واحدهاى يزوهش اطمينان داده شد كه ياسخهاى آنان تنها در جهت اهداف يزوهشى و دستيابى به راهكارهاى ارتقاى سلامت در خلبانان به

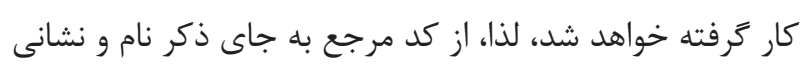

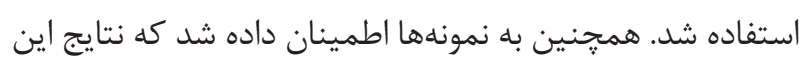
مطالعه فقط براى تهيه مقاله استفاده خواهد شد.

جدول ا - شاخصهاى توصيفى و ضريب همبستغى بين متغيرهاى تحقيق

\begin{tabular}{|c|c|c|c|c|c|c|}
\hline \multicolumn{4}{|c|}{ همسبتخى } & \multicolumn{3}{|c|}{ شاخصهاى توصيفى } \\
\hline عملكرد خانواده & استرس & افسردَى & اضطراب & انحراف معيار & ميانگَين & متغير \\
\hline $.1 \cdot 4$ &.$/ 11$ & $* \cdot / T r$ &.$/ 14$ & $\Delta / \Delta q$ & ra/Al & سن (سال) \\
\hline$\cdot 1 \cdot \mathrm{V}$ & .110 & * & .111 & $\Delta / r q$ & $r T / Y$. & سن همسر (سال) \\
\hline$\cdot 1 \cdot \wedge$ &.$/ 11$ & $* \cdot / r F$ & $* / \pi r$ & $9 / \pi \cdot$ & $11 / 99$ & سابقه كار (سال) \\
\hline \multirow[t]{4}{*}{$.1 \cdot 9$} & $.11 \mathrm{~V}$ & $*$ * & $\cdot /\left.1\right|^{\mathrm{F}}$ & $\Delta / g F$ & १/१ & مدتزمان ازدواج (سال) \\
\hline & & & 1 & $r / \cdots 1$ & N/q. & اضطراب \\
\hline & & 1 & $* / V r$ & r/gF & $q / r \Delta$ & افسردكى \\
\hline & 1 & $* \cdot 19 \Lambda$ & $* / V T$ & $F / r V$ & $9 / 94$ & استرس \\
\hline 1 & $* \cdot / T r$ & $* \cdot / r \Delta$ & $* \cdot|f|$ & $\mid r / \Delta \Lambda$ & $114 / 1$ & عملكرد خانواده \\
\hline$* \cdot|4|$ & $* \cdot 119$ & $.11 \mathrm{~V}$ & $* \cdot / r \mid$ & $1 / \wedge \Delta$ & $|T /| F$ & حل مسئله \\
\hline$* / r \Lambda$ & $* \cdot / \Delta r$ & * & $* \cdot / \& V$ & $r / \cdot V$ & $r \cdot / \cdot V$ & ارتباط يا تعامل \\
\hline$* / 4 V$ & $* \cdot / r F$ & $* \cdot|r|$ & $* / \mu q$ & 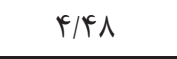 & $T Y / T \Delta$ & نقشها \\
\hline$* / 4 V$ & 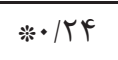 & $* \cdot / r \mid$ & $* / r \Delta$ & र/१९ & $10 / 79$ & آميزش عاطفى \\
\hline$* \cdot 199$ & $* \cdot / r$ & $* \cdot / T 1$ & $* \cdot / r \wedge$ & $r / \mathcal{F}$ & $19 / 11$ & كنترل عاطفى \\
\hline$* \cdot 9 r$ & $* \cdot|r|$ & $* \cdot / T F$ & $* \cdot / T V$ & $r / V F$ & $r r / r \Delta$ & ياسخ عاطفى \\
\hline
\end{tabular}


واريانس (Variance Inflation Factor: VIF) بررسى و مقدار آن بين •--1 مشخص شد. سيس جهت انجام ركرسيون اقدام

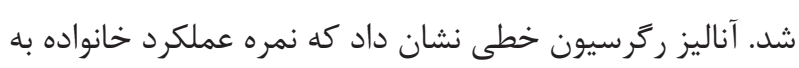

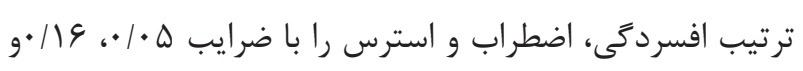

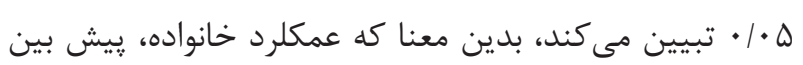

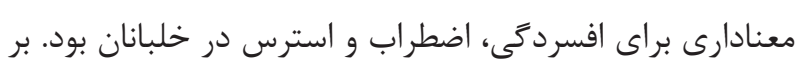

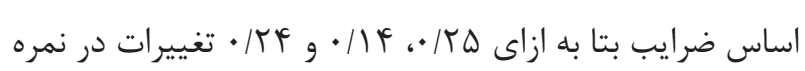
عملكرد خانواده به ترتيب يك واحد تغييرات معنادار در نمرات افسردگى، اضطراب و استرس شركت كنندكان ايجاد مى شود. افسردگى، استرس و اضطراب توانستند ابعاد عملكرد خانواده

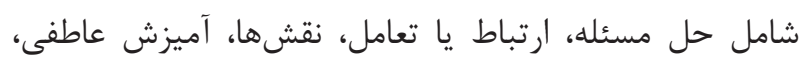

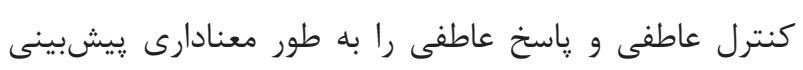

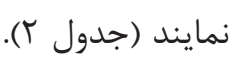

جهت تعيين سهم متغيرهاى پِيش بين در تبيين استرس،

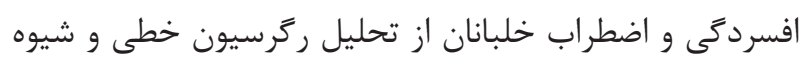
ورود استفاده شد. قبل از اجراى اين روش آمارى (Enter Method)

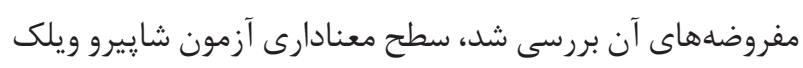
(Shapiro-Wilk) دادهها است. مقدار آماره دوربين واتسن (Durbin- Watson)،

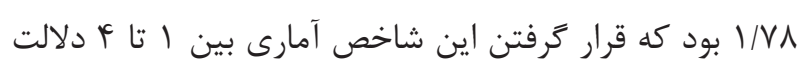
بر مستقل بودن باقيماندهها در ركرسيون دارد. علاوه بر اين،

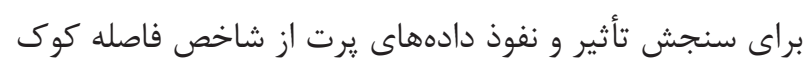
(Cook)

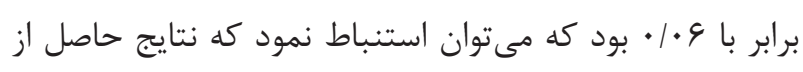

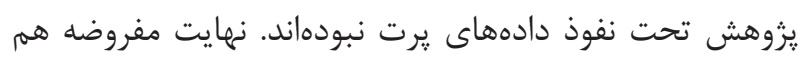

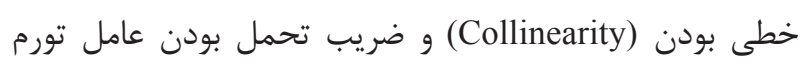

جدول ץ- آناليز ركر سيون خطى جهت يِشبينى نمره كل اختلال در عملكرد خانواده بر اساس نمرات افسردكى، اضطراب و استرس

\begin{tabular}{|c|c|c|c|c|c|}
\hline $\mathbf{T}$ & $\beta$ & ضرايب غير استاندارد & RY & متغير & متغير پيش بين \\
\hline$* T / 9$ & $\cdot / \pi \Delta$ & $.1 \cdot 9$ & $* \cdot 1 \cdot \Delta$ & نمره افسردگى & \multirow{3}{*}{ عملكرد خانواده } \\
\hline$* y / 9 r$ & $\cdot|4|$ & $\cdot .9$ & $* \cdot 119$ & نمره اضطراب & \\
\hline$* Y / \Delta \Delta$ & $\cdot M F$ & $\cdot 1 \cdot \mathrm{V}$ & $* \cdot 1 \cdot 0$ & نمره استرس & \\
\hline I/VA & $\cdot 1 \cdot 0$ & $\cdot 1 \cdot 1$ & $\cdot / \cdot r$ & نمره افسردگى & \multirow{3}{*}{ حل مسئله } \\
\hline$* \Gamma / 1$ &.$/ 11$ & $\cdot 1 \cdot 0$ & $\cdot 1 \cdot \mathrm{f}^{\mathrm{f}}$ & نمره اضطراب & \\
\hline$* 1 / 99$ & .119 & $\cdot / \cdot r$ & $\cdot 1 \cdot t^{c}$ & نمره استرس & \\
\hline$* T / 9 V$ & $\cdot / \pi V$ & $\cdot|\pi|$ &.$/ 11$ & نمره افسردگى & \multirow{3}{*}{ ار ارتباط } \\
\hline$* Q / / F T$ & $\cdot / 4 V$ &.$/ 4 \lambda$ &.$/ 4 t$ & نمره اضطراب & \\
\hline *G/Tr &.$/ Q T$ & $\cdot / \mu V$ & $\cdot / 4 \lambda$ & نمره استرس & \\
\hline$* Y / T 1$ & $\cdot|r|$ & .148 & $\cdot 1 \cdot t^{f}$ & نمره افسردگى & \multirow{3}{*}{ نقشها } \\
\hline$* 4 / r q$ & $\cdot / 49$ & $\cdot 101$ &.$/ 14$ & نمره اضطراب & \\
\hline$* T / \Delta T$ & $\cdot / K F$ &.$/ T F$ & $\cdot 1 \cdot \Delta$ & نمره استرس & \\
\hline$* T / 19$ & $\cdot|\pi|$ &.$/ 1 \mathrm{~V}$ & $\cdot 1 \cdot r$ & نمره افسردگى & \multirow{3}{*}{ آميزش عاطفى } \\
\hline$* T / 9 V$ & $\cdot \pi \Delta$ &.$/ M Y$ &.$/ 11$ & نمره اضطراب & \\
\hline$* Y / \Delta \varphi$ & $\cdot / T F$ & .119 & $\cdot 1 \cdot \Delta$ & نمره استرس & \\
\hline *T/TY & $\cdot|\pi|$ & $\cdot / T$ & $\cdot / \cdot r$ & نمره افسردگى & \\
\hline$* \pi / \cdot r$ & $\cdot / r \Lambda$ & ת זس/. & $\cdot 1 \cdot V$ & نمره اضطراب & كنترل عاطفى \\
\hline$* T / \cdot \Delta$ & $\cdot \pi$ & .110 & $\cdot 1 \cdot r$ & نمره استرس & \\
\hline$* r / \Delta \Delta$ & $\cdot / T F$ & $\cdot / T \Delta$ & $\cdot 1 \cdot \Delta$ & نمره افسردگى & \\
\hline *Y/AG & $\cdot / T V$ & $\cdot / \mu F$ & $.1 \cdot 9$ & نمره اضطراب & پِاسخ عاطفى \\
\hline$* T / 19$ & $\cdot|\pi|$ & .111 & $\cdot 1 \cdot r$ & نمره استرس & \\
\hline
\end{tabular}


جستجوهايى كه در منابع معتبر علمى و قابل دسترس داشتهاند، به مطالعه ناهمسو با نتايج مطالعهشان دست نيافتند.

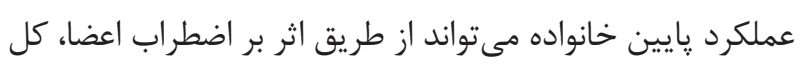

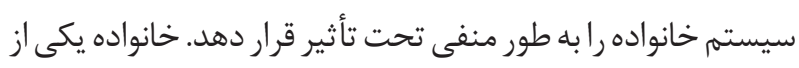

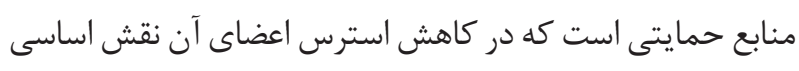

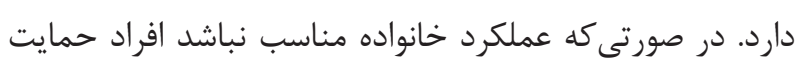

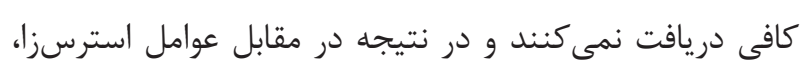

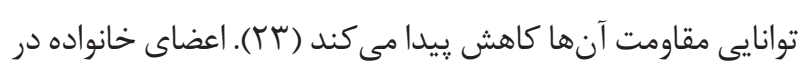

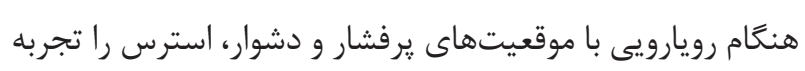

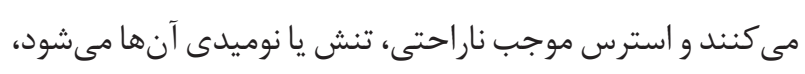

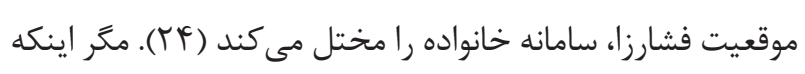
خانواده بتواند خود را با وضعيت تازه ساز حار نمايد. براى اينكه خانواده به عملكرد عادى خود بازَر دد و مشكل ران ران خل نمايد نياز

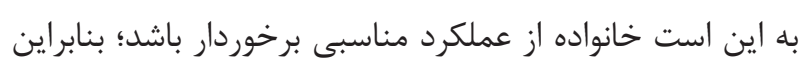

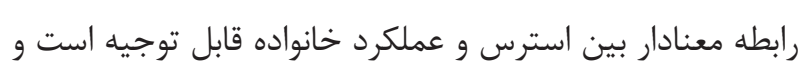
خانواده در بيشخيرى از استرس نقش حمايتى دارد. محيط كار

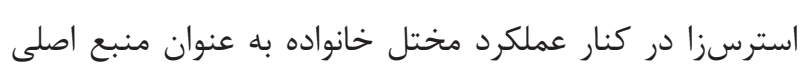

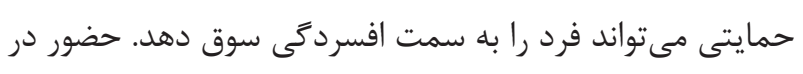
يك خانواده سالم با كاركرد مناسب مى تواند از طريق ايجاد اميد و فراهم نمودن حمايت روانى از احساس نا اميدى و افسردخى بكاهد.

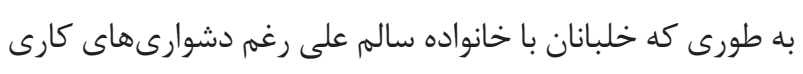
در صورتى كه محيط خانوادگى مناسبى داشته باشند. با اشتياق و اميد بالاترى كار كنند. از ميان متغيرهاى جمعيت شناختى تنها سابقه كار با ميزان

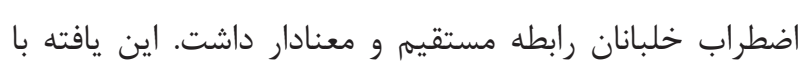

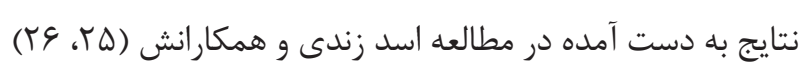
كه نشان داد با افزايش سابقه كار ميزان اضطراب كاهش بـ بيدا مى كند ناهمخوان است. علت اين تفاوت مى تواند مربوط به تفاوت ماهيت شغل يرستارى و خلبانى باشد از طرفى يرستاران با افزايش

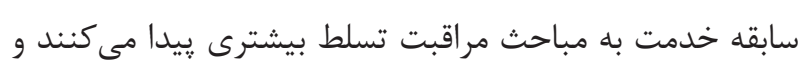

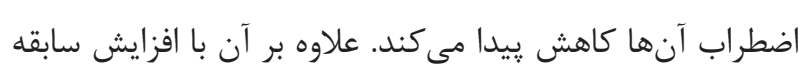
كار ميزان ساعات كارى آنها تعديل مى شود. همسو با يافتههاى

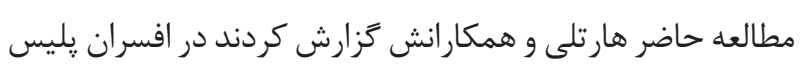
با افزايش سالهاى خدمت ميزان اضطراب افزايش پِيدا مى كند

\section{بحث و نتيجه كيرى}

مطالعه حاضر با هدف بررسى ارتباط عملكرد خانواده با استرس، اضطراب و افسردگى خلبانان نيروى هوايى اصفهان انجام شد.

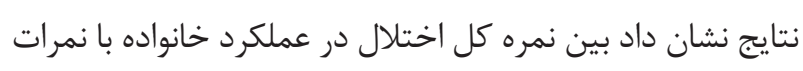
اضطراب، افسردگى و استرس رابطه مستقيم وجود دارد، بدين معنا

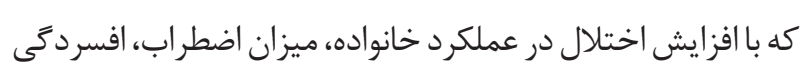

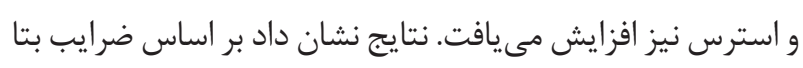

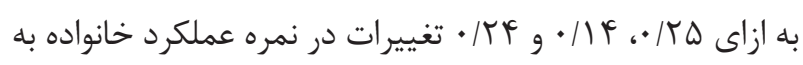
ترتيب يك واحد تغييرات معنادار در نمرات افسردگى، اضطراب و استرس شركت كنندگًان ايجاد مى شد. در مطالعهاى كه مارلين

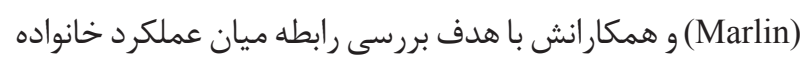

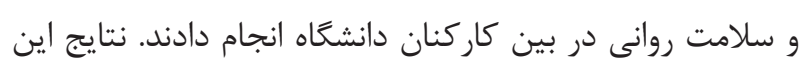

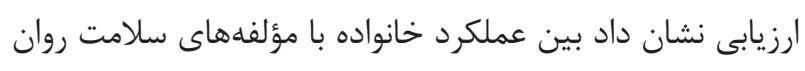

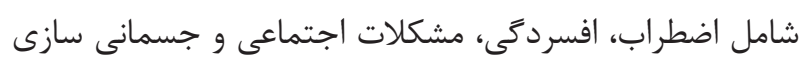

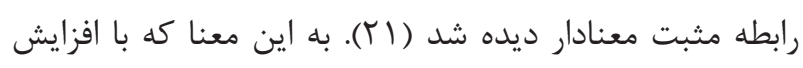

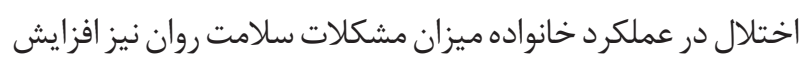
مى يافت. اين يافته با نتايج مطالعه حاضر همسو مى بـاشداند.

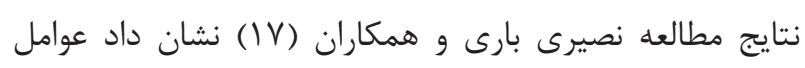

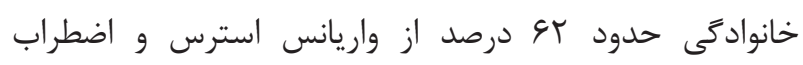

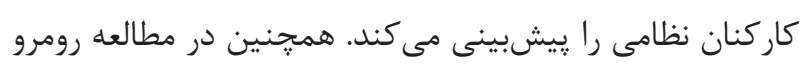

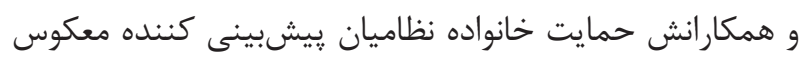

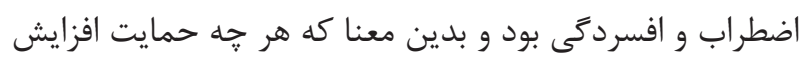

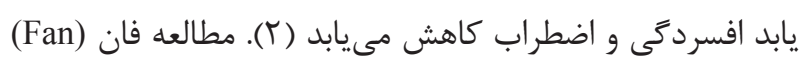

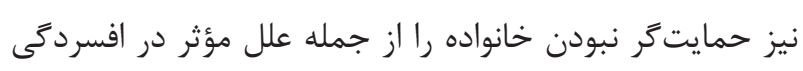
كار كنان نظامى مىشود (IV) همجنان كه هاگز (Hughes) و همكارانش نيز با بررسى بزر تسالان

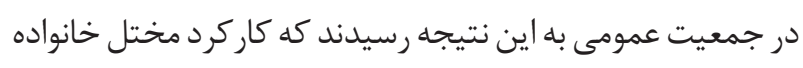

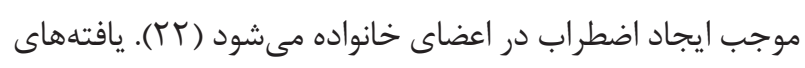

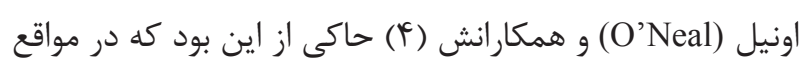

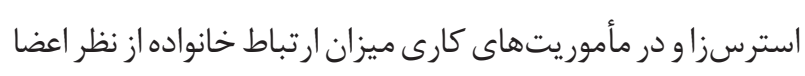
بهلطور محسوسى كاهش ييدا مى كرد و بعد از اتمام مأموريت نيز

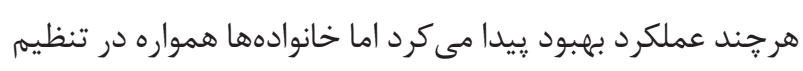

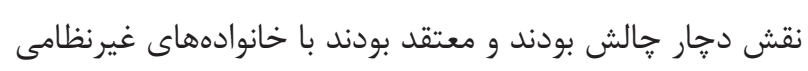

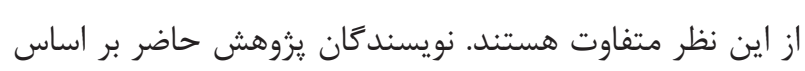


شده بود يا شركت كننده به تمام سؤالات پاسخ يكسان داده بود. محدوديت ديخر عدم امكان شركت دادن ديخر اعضاى خانواده

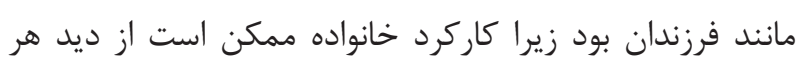

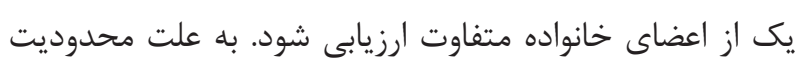

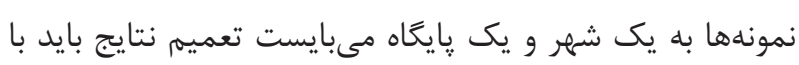

$$
\text { احتياط صورت گيرد. }
$$

نتايج حاكى از اين بود كه عملكرد خانواده خلبانان نظامى مى تواند

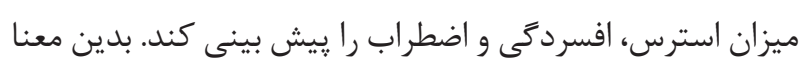

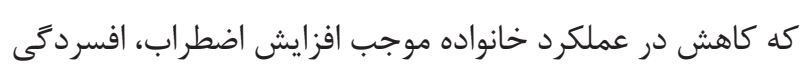

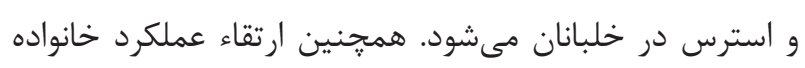

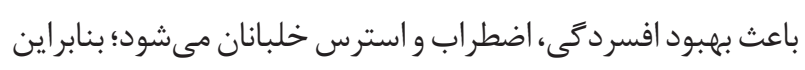
ريشنهاد مىشود عملكرد خانوادهها در نظاميان بيشتر مورد توجه قرار كيرد.

$$
\text { تشكر و قدردانى }
$$

نويسند يزوهشى دانشكاه علوم يزشكى اصفهان تشكر نمايند. از يرويوزال

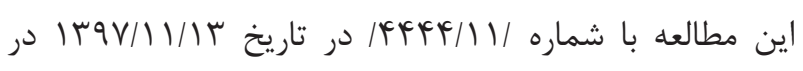
دانشكده يرستارى مامايى دانشكده علوم يزشكى اصفهان دفاع صورت گرفته است.

\section{تضاد منافع}

بدين وسيله كليه نويسند منافعى در خصوص مطالعه حاضر وجود ندارد.

\section{References}

1- Resick PA, Wachen JS, Dondanville KA, Pruiksma KE, Yarvis JS, Peterson AL, et al. Effect of Group vs Individual Cognitive Processing Therapy in Active-Duty Military Seeking Treatment for Posttraumatic Stress Disorder: A Randomized Clinical Trial. JAMA Psychiatry. 2017;74(1):28-36. DOI: 10.1001/ jamapsychiatry.2016.2729 PMID: 27893032

2- Romero DH, Riggs SA, Ruggero C. Coping, family social support, and psychological symptoms among student veterans. J Couns Psychol. 2015;62(2):242-52. DOI: 10.1037/cou0000061 PMID: 25643161

3- Shahbazi A, Ghorbanzadeh A, Yazdi G, Azad M, Sharifi A. Comparing the effect of lecture and rescue training methods with
(TV) (Y در توجيه اين يافته مىتوان Fفت با افزايش سال هاى خدمت

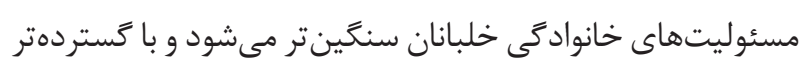

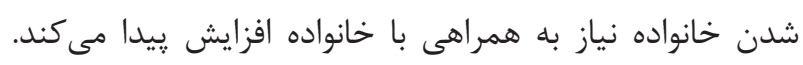

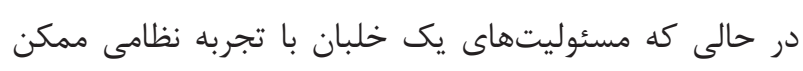

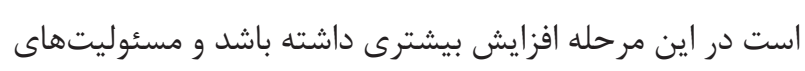

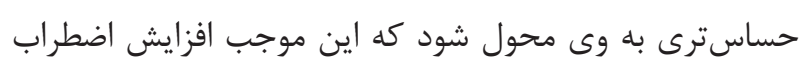
مىشود. ريشنهاد مىشود نظر به اهميت شغل خلبانى و حساسيت نقش

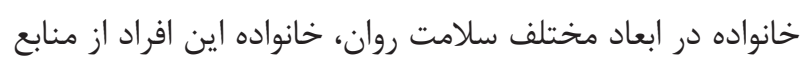

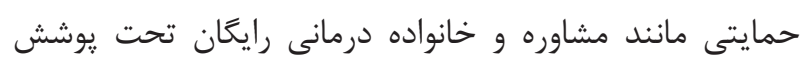

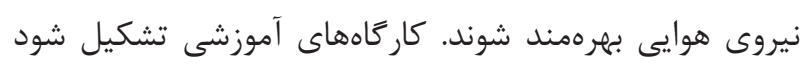
كه در طى آن همسران از نقشهاى همديخر و فشار مسئولىها

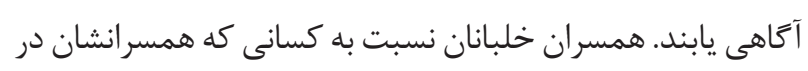
مشاغل عادى و كمخطر مشغول به كار هستند استرس و نتخرانى

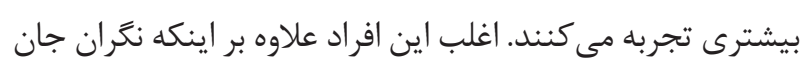

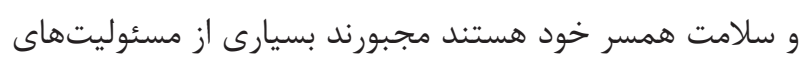

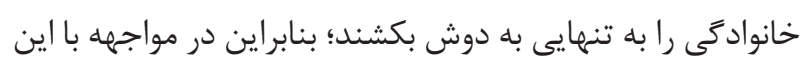

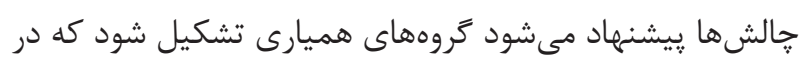

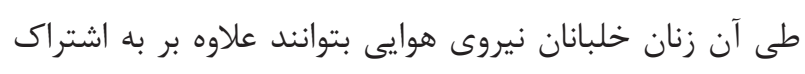
كذاشتن تجربيات خود با اعضاى كروه حمايت روانى دريافت كنيند.

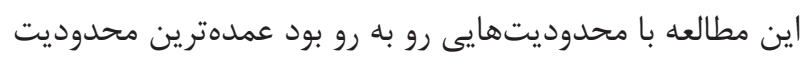

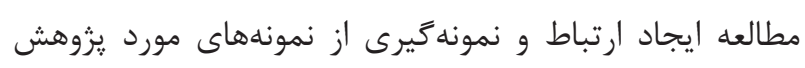

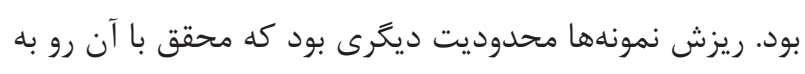

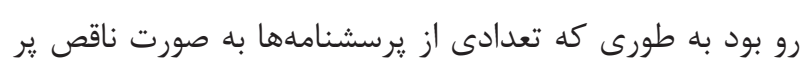

the war maneuvers on the public aid preparedness in the personnel of the navy's military barracks. J Military Med. 2016;17(4):291-7.

4- O’Neal C, Lucier-Greer M, Duncan J, Mallette J, Arnold A, Mancini J. Vulnerability and Resilience within Military Families: Deployment Experiences, Reintegration, and Family Functioning. J Child \& Family Studies. 2018;27(10):3250-61. DOI: 10.1007/ s10826-018-1149-6

5- Fornette M, Bardel M, Lefrançois C, Fradin J, Massioui F, Amalberti R. Cognitive-Adaptation Training for Improving Performance and Stress Management of Air Force Pilots. The International J Aviation Psychology. 2012;22(3):203-23. DOI: 10.1080/10508414.2012.689208 
6- Hubner M, Peirson R, Puchta P, McBride T. A Reconceptualization of the Adaptability Rating for Military Aviation. USAFSAM Wright-Patterson AFB United States, 2017.

7- Dismukes R, Goldsmith TE, Kochan JA. Effects of acute stress on aircrew performance: literature review and analysis of operational aspects. Technical Report. 2015;1(1):13.

8- Nasioudis D, Palaiodimos L, Dagiasis M, Katsarou A, Ntouros E. Depression in military medicine cadets: a cross-sectional study. Mil Med Res. 2015;2:28. DOI: 10.1186/s40779-015-0058-x PMID: 26557991

9- Rahnejat A. The Impact of Stress on the Performance of Pilots and Military Personnel Staff and its Control Methods. Second Congress of Aerospace and Subsurface Medicine2012. p. 1-10.

10- Chappelle W, Goodman T, Reardon L, Thompson W. An analysis of post-traumatic stress symptoms in United States Air Force drone operators. J Anxiety Disord. 2014;28(5):480-7. DOI: 10.1016/j. janxdis.2014.05.003 PMID: 24907535

11- Wu AC, Donnelly-McLay D, Weisskopf MG, McNeely E, Betancourt TS, Allen JG. Airplane pilot mental health and suicidal thoughts: a cross-sectional descriptive study via anonymous webbased survey. Environ Health. 2016;15(1):121. DOI: 10.1186/ s12940-016-0200-6 PMID: 27974043

12- Ahmadi M, Karimi H. The effect of organizational factors on the performance of passenger pilots with regard to the moderating role of environmental factors. J Aeronautical Engineering. 2017;18(2):69-84

13- Jongerden L, Bögels S. Parenting, Family Functioning and Anxiety-Disordered Children: Comparisons to Controls, Changes After Family Versus Child CBT. J Child \& Family Studies. 2014;24(7):2046-59. DOI: 10.1007/s10826-014-0005-6

14- Sheidow AJ, Henry DB, Tolan PH, Strachan MK. The Role of Stress Exposure and Family Functioning in Internalizing Outcomes of Urban Families. J Child Fam Stud. 2014;23(8):135165. DOI: 10.1007/s10826-013-9793-3 PMID: 25601821

15- Kohan S, Heidari Z, Keshvari M. Iranian Women's experiences of breastfeeding support: a qualitative study. Inter J Pediatrics. 2016;4(10):3587-600.

16- Nasiri- Bari H, Peivastehghar A, Derakhshani A. Investigation and rioritization of factors affecting the job stress of commanders and military managers. Military Management. 2013:131-54.

17- Fan LB, Blumenthal JA, Watkins LL, Sherwood A. Work and home stress: associations with anxiety and depression symptoms. Occup Med (Lond). 2015;65(2):110-6. DOI: 10.1093/occmed/ kqu181 PMID: 25589707

18- Yoosefi N. An investigation of the psychometric properties of the mcmaster clinical rating scale (MCRS). Education Measurments. 2012;2(7):91-120.

19- Afzali A, Delawar A, Burjali A, Mirzamani M. Psychometric properties of DASS-42 test based on a sample of high school students in Kermanshah. Journal of Behavioral Sciences Research. 2007;2(5):81-92.

20- Asghari Moghadam M, Foad S, Dibaj Nia P, Zanganeh J. Preliminary Investigation of the Validity and Reliability of Depression, Anxiety and Stress Scales (DASS) in Nonclinical Samples. Behavioral Scientist. 2008;15(11):23-38.

21- Marlin AF. The Study of the relationship between family functioning and mental health among the employees of Kurdistan University of Medical Sciences. Scientific J Nurs, Midwif \& Paramed Faculty. 2016;2(1):12-21.

22- Hughes AA, Hedtke KA, Kendall PC. Family functioning in families of children with anxiety disorders. J Fam Psychol. 2008;22(2):325-8. DOI: 10.1037/0893-3200.22.2.325 PMID: 18410220

23- Momeni K. The Relationship between Family Functioning, Differentiation of Self and Resiliency with Stress, Anxiety and Depression in the Married Women Kermanshah city. Family Research. 2013;2(10):293-312.

24- Pollock E, Kazman J, Deuster P. Family Functioning and Stress in African American Families. J Black Psychology. 2014;41(2):14469. DOI: $10.1177 / 0095798413520451$

25- Chatters LM, Nguyen AW, Taylor RJ, Hope MO. Church and Family Support Networks and Depressive Symptoms among African Americans: Findings from the National Survey of American Life. J Community Psychol. 2018;46(4):403-17. DOI: 10.1002/jcop.21947 PMID: 29755153

26- Asad Zandi M, Sayari R, Ebadi A, Sanainasab H. Abundance of depression, anxiety and stress in militant Nurses. J Mil Med. 2011;13(2):103-8.

27- Hartley T, Violanti J, Mnatsakanova A, Andrew M, Burchfiel C. Military experience and levels of stress and coping in police officers. Inter J Emergency Mental Health. 2013;15(4):229. 